\title{
Abordagem funcional de arquivos pessoais: reflexões a partir do Arquivo Epifânio Dória
}

Lorena de Oliveira Souza Campello

Instituto Histórico e Geográfico de Sergipe (IHCSE).

Resumo

O objetivo do artigo em questão é discutir a importância do tratamento dos arquivos pessoais como arquivos, sendo merecedores de uma abordagem arquivística adequada. Para tanto, faremos uma demonstração fundamentada de um procedimento metodológico com arquivos pessoais, a partir do estudo de caso do arquivo de Epifânio Dória, tendo como resultado principal inventário cronológico do conjunto documental e índice estratificado. 0 arquivo é custodiado pelo Instituto Histórico e Ceográfico de Sergipe, estando sob a responsabilidade da Seção de Biblioteca e Arquivo.

Palavras-chave: Arquivos pessoais; Abordagem funcional; Epifânio Dória; Inventário cronológico; Índice estratificado.

\author{
Functional approach of personal \\ archives: reflections from Epifânio \\ Dória's archive
}

\section{Abstract}

The goal of this article is to discuss the importance of treating archives as proper archives that deserve an appropriate archivistic approach. Therefore, we offer a demonstrationfoundedona methodological procedure with personal files, using as case study Epifânio Dória's archive. As main result, the text presents the chronological inventory and the and stratified index of this archive: The archive is guarded by the Historical and Ceographic Institute of Sergipe, being under the responsibility of the Library and Archive Section.

Keywords: Personal archives; Functional approach; Epifânio Dória; Chronological inventory; Stratified index. 


\section{In t r o d u ça}

- odos nós desenvolvemos inúmeras funções e atividades ao longo de nossa vida. A trajetória de cada pessoa delimita especificidades ao conjunto documental acumulado por ela. Assim, cada arquivo pessoal apresenta documentos ligados aos tipos de atividades e funções desempenhadas por esses indivíduos: ligações institucionais fomentadas, relações de amizade mantidas, opções intelectuais e os gostos cultivados pelo titular desse arquivo.

Viver em sociedade implica produzir, receber e acumular documentos. Estes são instrumentos essenciais para o funcionamento da vida em sociedade e, portanto, testemunhos da trajetória de qualquer pessoa.

Os arquivos pessoais não são criados com finalidade histórica e cultural, mas sim acumulados com uma funcionalidade clara para a pessoa que o formà. A projeção do "eu" não existe no arquivo pessoal, e se assim ocorrer, não a podemos considerar como um arquivo. Desse modo, os documentos são acumulados para cumprir certa função por força probatória (carregada pela forma e pelo contexto do documento em si), ainda que seja de ordem psicológica.

A função instrumental é condição primordial para que exista o arquivo, sem preocupações com o olhar alheio e o do futuro. Por assim dizer, o arquivo é um conjunto articulado de documentos produzidos, recebidos e acumulados, de caráter instrumental.

A variedade de tipos documentais encontrados nos arquivos pessoais é extensa. $O$ que pode ser identificado em um arquivo poderá não ser visto em outro, pois as pessoas são únicas e desenvolvem atividades, funções e papéis distintos na sociedade em que atuam.

Porrefletirem, mesmo quenão totalmen- 
te, a vida de alguém, os arquivos pessoais fazem com que tenhamos a sensação de estarmos acompanhando a trajetória de seu titular. Quanto mais os documentos desse arquivo revelam os pormenores, os eventos e as atividades desempenhadas pelo indivíduo, mais nos aproximamos de sua vida.

Alimentar a discussão sobre a importância do tratamento dos arquivos pessoais como arquivos, sendo merecedores, portanto, de uma abordagem arquivística adequada, é nosso objetivo principal. Para tanto, faremos uma demonstração fundamentada de um procedimento metodológico com arquivos pessoais, a partir do estudo de caso do arquivo de Epifânio Dória, bibliotecário e historiador sergipano dedicado à pesquisa, difusão e proteção do patrimônio documental de Sergipe, tendo como resultado principal o inventário cronológico do conjunto documental eseus instrumentos auxiliares?

1Esse trabalho consiste numa síntese da tese de doutorado "O legado documental de Epifânio Dória: por uma abordagem funcional dos arquivos pessoais", apresentada ao Programa de Pós-Graduação em História Social, da Universidade de São Paulo. Cf: CAMPELLO, Lorena de Oliveira Souza. O legado documental de Epifânio Dória: por uma abordagem funcional dos arquivos pessoais. 2015. Tese (Doutorado em História Social) - Faculdade de Filosofia, Letras e Ciências Humanas, Universidade de São Paulo, São Paulo, 2015. doi:10.11606/T.8.2015.tde-06112015-153452. Acesso em: 2016-12-08. Essa pesquisa foi financiada pela Fundação de Amparo'à Pesquisa do Estado de São Paulo (Fapesp).
O instrumento de pesquisa em questão reuniu, intelectualmente, a documentação acumulada pelo intelectual sergipano Epifânio Dória. Trata-se de um inventário cronológico, o qual tem por finalidade travar um diálogo exaustivo entre a documentação produzida e acumulada por seu titular e sua trajetória de vida - entendendo-se diálogo não como uma interpretação histórica, mas como a construção de uma ponte entre o(s) documento(s) e a atividade/evento que the $(s)$ deu origem.

O arquivo de Epifânio Dória agrupa 35.193 documentos, estando distribuído e consequentemente fragmentado - em três importantes instituições sergipanas, Instituto Histórico e Ceográfico de Sergipe (IHCSE), Arquivo Público do Estado de Sergipe (APES) e Biblioteca Pública Estadual Epifânio Dória (BPED)². Apesar de fisicamente fragmentado, trata-se de um arquivo íntegro, preservado pela família e, posteriormente, pelas instituições de custódia que o receberam.

Considerando que lidamos com um arquivo fragmentado e não classificado, uma vez que os 28.500 documentos pertencentes ao arquivo custodiado

2 Optamos por usar, a partir deste momento do texto, as siglas destas três instituições de custódia como forma de agilizar a leitura. 
pelo IHCSE não estavam endereçados, e levando em conta o volume do conjunto documental (35.193 documentos), o plano de classificação convencional não cumpriria com nosso objetivo. Acreditamos que o plano de classificação que toma como ponto de partida grandes categorias gera ambiguidades e polissemias, bem como não leva em consideração as especificidades das trajetórias de vida das pessoas que, a bem dizer, são únicas.

Optamos, desse modo, por uma nova abordagem. A classificação assumiu o patamar mais próximo dos documentos, ou seja, os documentos foram classificados um a um, elegendo, com isso, a escala micro, de modo a apreciar as peculiaridades da trajetória de vida do titular do arquivo. Nesse sentido, foram os verbetes os elementos de classificação que deram um sentido mais imediato aos documentos. Ao analisarmos documento por documento, fizemos a ligação destes com a atividade mais imediata de sua produção. Os documentos apontaram, simultaneamente, para a atividade que os originou, ganhando sentido.

Ressaltamos aqui que não negamos a função macro, pois reconhecemos que esta possibilita o acesso dos usuários a estratos significativos e variados da vida do titular de um arquivo. Nesse sentido, fornecemos também ao usuário um índice multifacetado, o qual sinaliza estratos da trajetória de vida de Epifânio Dória.

Com o intuito de expandir as possibilidades de busca, potencializando assim o acesso à documentação, fornecemos ainda um índice geral, que remete aos verbetes do inventário cronológico; um índice de publicações (de Epifânio Dória e outros autores); um glossário de documentos; além de um índice estratificado, apresentando uma outra opção de pesquisa a partir das esferas da vida do titular do arquivo.

0 instrumento de pesquisa fornece informações valiosas sobre Epifânio Dória e sua época, tais quais: o relacionamento que manteve com seus contemporâneos, suas redes de sociabilidade, as ferramentas de pesquisa por ele utilizadas, os valores compartilhados com amigos e conhecidos, os contatos que teve com os poderes constituídos. Trata-se do retrato de um intelectual, próprio de uma época.

Enfim, o arquivo de Epifânio Dória é representativo das atividades por ele desenvolvidas, seja na esfera pessoal, familiar ou profissional. Resgatar parte da trajetória da vida de Epifânio Dória, por meio do que foi produzido e acu- 
mulado por ele, é uma forma de fazer conhecer com mais profundidade esse intelectual, assim como tantos que se fazem presentes nesses documentos por meio das relações sociais que mantiveram com o titular.

\section{Epifânio Dória e seu arquivo}

Mas, por que o interesse em desenvolver um estudo de caso e, subsequentemente, propor uma metodologia voltada para o trabalho com arquivos pessoais, buscando a correlação entre a contextualização da documentação acumulada e a história de vida de Epifânio da Fonseca Dória e Menezes? Quem foi esse homem? Por que a escolha dessearquivo pessoal para direcionara pesquisa? A primeira razão diz respeito ao titular, que foi figura representativa em Sergipe por sua contribuição à guarda, preservação de documentos históricos e arquivos pessoais de personalidades sergipanas, notabilizando-se, inclusive, pela incansável pesquisa histórica desenvolvida ao longo de sua vida.

A segunda razão decorre da possibilida- de de descrever a arquivo pessoal de um historiador e intelectual próprio de uma época, um pesquisador erudito e genera-, lista, com interesses voltados para a história e a cultura de Sergipe e do Brasil. ${ }^{3}$

A terceira razão está ligada à configuração do arquivo pessoal de Epifânio Dória, um fundo fechado, cujos documentos estão distribuídos em mais de uma instituição de guarda (Instituto Histórico e Ceográfico de Sergipe (IHCSE), Arquivo Público do Estado de Sergipe (APES) e Biblioteca Pública Estadual Epifânio Dória (BPED) - que oferece possibilidades de discussões sobre os princípios da integridade/indivisibilidade, proveniência e organicidade arquivística, além de refletir sobre a fragmentação do arquivo e suas consequências, bem como outros aspectos.

A quarta e última razão está na fortuna do conjunto documental, que perfaz um período riquíssimo da história do Brasil, marcado por acontecimentos e transições importantes, que apresentam para o pesquisador inúmeras possibilidades de pesquisa em diversas

3 De uns anos para cá, vêm sendo desbravados arquivos pessoais de artistas, músicos, literatos e cientistas, mas ainda é ínfimo o trato com arquivos pessoais de historiadores. 


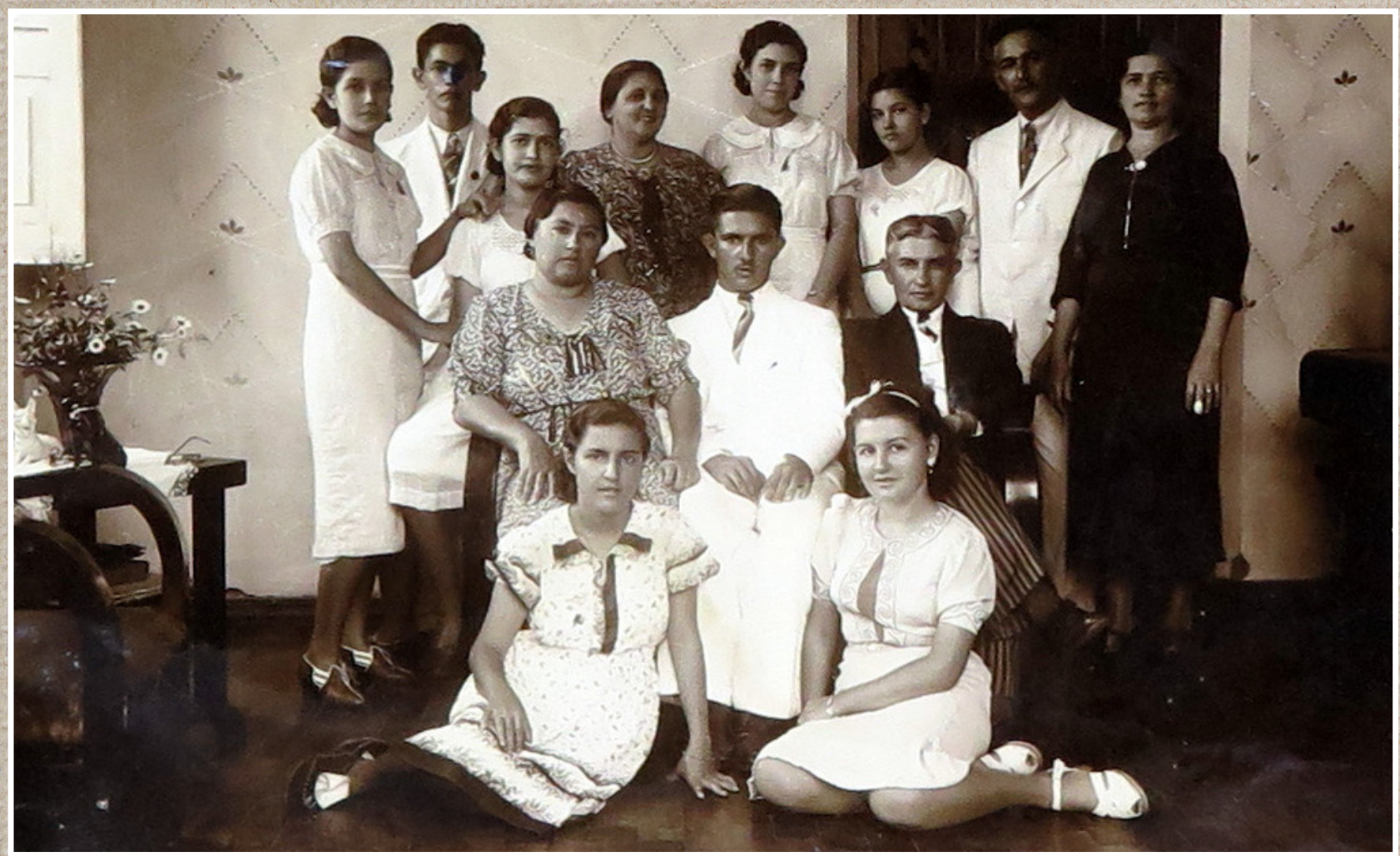

Imagem 1-Epifânio Dória e família reunida.

Fonte: Arquivo da família

áreas do conhecimento, como bem demonstra trabalho apresentado no Encontro de Arquivos Pessoais e Culturas, promovido pela Casa de Rui Barbosa4.

4 Pelo envolvimento direto de Epifânio Dória com a política getulista e com o Estado Novo, ao assumir a pasta de Secretário Geral do Estado de Sergipe, e pela sua relação atuante no Partido Republicano de Sergipe, seu arquivo fornece uma rica documentação para os que se interessam pela história política desse período: Considerando que Epifânio Dória vivenciou o processo do golpe militar e quase todo o período do regime militar no Brasil, a correspondência que manteve com dezenas de amigos, de diversos estados da federação, e de envolvimento partidário e posicionamento ideológico distintos é brilhante. Outro aspecto muito interessante a ser explorado a partir do conjunto documental discutido é o da intelectualidade cultural brasileira e sergipana, durante as primeiras seis décadas do século $X X$, e suas transformações com a presença cada vez mais marcante da's universidades. A documentação produzida e acu-
Filho de proprietários de terras, Epifânio da Fonseca Dória e Menezes nasceu no ano de 1884, em Campos (atual Tobias Barreto), estado de Sergipe.

mulada para a produção de determinado texto, reunida em torno do seu,contexto de produção, facilita a percepção e o estudo de como funcionava a produção do conhecimento e a escrita da história, durante as sete primeiras décadas do século XX. Ainda dentro dessa temática, temos as cartas e os telegramas trocados com inúmeros amigos intelectuais, na constante busca pela fomentação da pesquisa, revelando uma fértil teia de relações e troca de conhecimentos, muito peculiares desse período. O mapeamento da rede de sociabilidade de Epifânio Dória por meio de sua correspondência (cartas, telegramas, cartões-postais, etc) é possível e pode apresentar resultados interessantíssimos. O trabaIho "O arquivo de Epifânio Dória: abordagem arquivística e possibilidades de pesquisa" foi apresentado no Encontro de Arquivos Pessoais e Culturas, promovido pela Casa de Rui Barbosa, no Rio de Janeiro, em novembro de 2014. 
Devido a intempéries na vida e nos negócios familiares, não teve grandes possibilidades de estudo, tendo concluído apenas o curso primário, o que não impossibilitou que ocupasse espaços importantes nas esferas pública e política de Sergipe. O resultado do seu autodidatismo e de seu trabalho foi a participação na formação de praticamente todos os centros de estudo, arquivos, bibliotecas, revistas e instituições dedicadas às humanidades no estado. Dedicou-se com

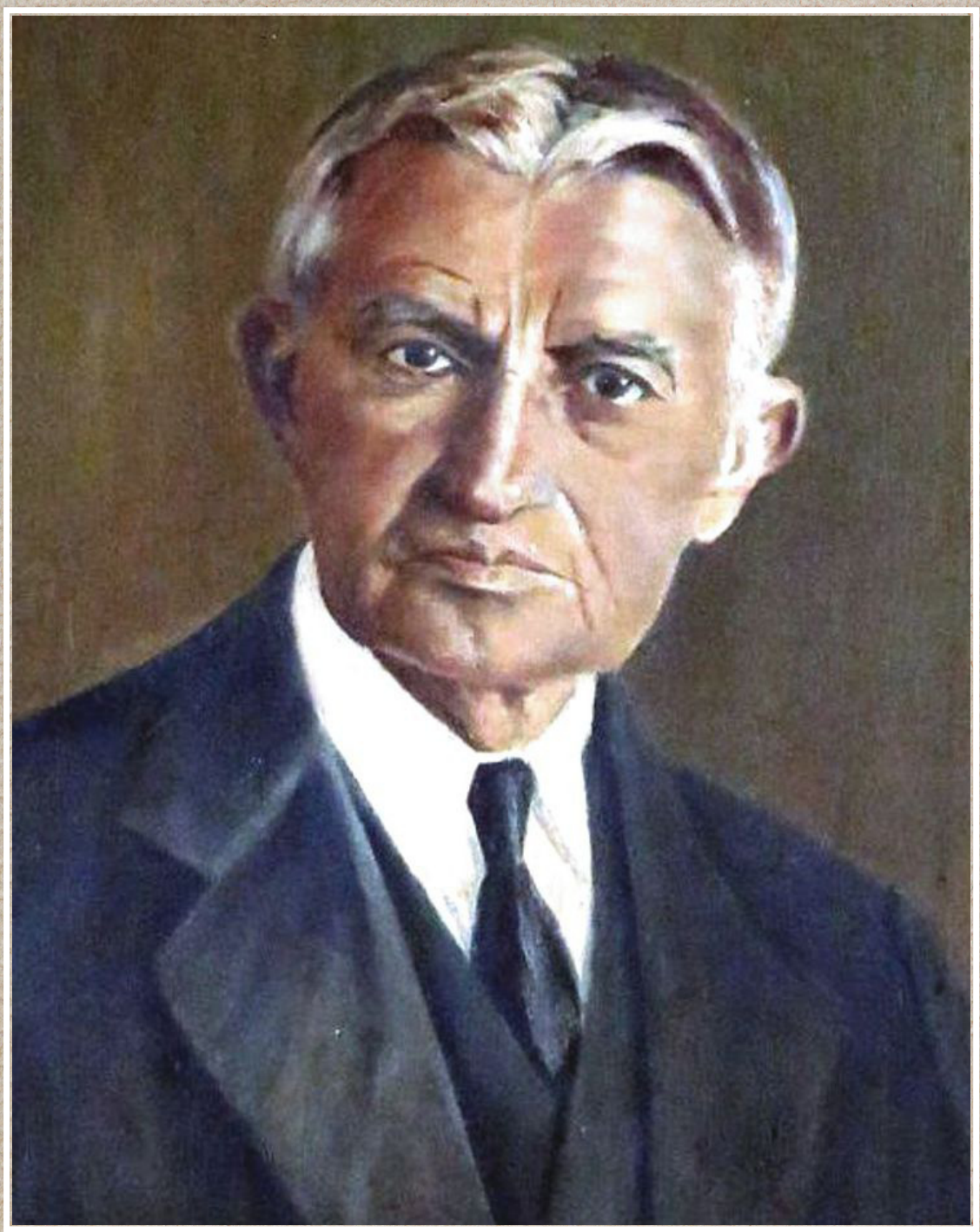

Imagem 2-Epifânio Dória, em tela de Florival Santos.

Fonte: Arquivo Epifânio Dória (IHCSE).

afinco à organização de arquivos por seis décadas, reunindo documentos, angariando recursos e adquirindo fundos $^{5}$.

Ao falecer, em junho 1976, aos 92 anos de idade, Epifânio Dória nos deixou um grande legado de acúmulo e vigilância de grandes acervos bibliográficos e arquivos sergipanos; de pesquisa

5 Para o histórico completo do titular ver Campello (2015). nas áreas da história, cultura e folclore sergipano; e de material escrito e publicado por ele em livros, revistas e jornais, sergipanos e nacionais.

Mas, apesar da importância que teve como homem envolvido com a preservação de acervos nas instituições de documentação de Sergipe, como divulgador da história e cultura sergipana, sua 
trajetória de vida continua inexplorada e seus documentos pessoais não receberam tratamento arquivístico adequado.

Uma das particularidades do titular do arquivo pessoal inventariado foi sua ligação, presença e circulação por praticamente todas as instituições de documentação, de cultura e de intelectualidade de Sergipe. Bibliotecário, historiador e pesquisador por prática e autodidatismo, Epifânio Dória esteve envolvido na vida administrativa e na esfera organizacional desses espaços. Dessa grande e intensa atividade não é de se estranhar a produção, recepção e acumulação de farta documentação relativas às instituições a que esteve vinculado.

Dessas ligações, em que se misturava o trabalho com a prática da pesquisa histórica, queremos destacar aqui sua relação com três instituições em específico: $\mid H G$ SE, APES e BPED. Por que tais locais? Dória dedicou ao IHGSE 64 anos de sua vida; fomentoua criação do APES, sendo, além de seu diretor por alguns anos, assíduo pesquisador dos documentos custodiados pela instituição; já à BPED, dedicoú mais de 30 anos de trabalho como bibliotecário e diretor.

Seu arquivo foi mantido sob a custódia de sua filha, Iracema Dória e, em momentos distintos, foi doado às instituições mencionadas : A situação em que se encontra o arquivo de Epifânio Dória nos impôs problemas práticos e teóricos complexos, mas, em contrapartida, nos ofereceu a chance de discuti-los, buscando soluções e propostas no desenvolvimento da pesquisa.

\section{O arquivo de Epifânio Dória e sua abordagem como arquivo}

Podemos afirmar que os documentos que compõem o arquivo de Epifânio Dória são documentos de arquivo, pois se tratam, notoriamente, de registros dos exercícios diários de uma atividade profissional, produzidos e acumulados por seu titular, portanto pelo mesmo produtor. Documentos recebidos por Epifânio Dória medianteas relações institucionais 
e sociais mantidas por ele. Documentos reunidos e acumulados pelo titular do arquivo com objetivo de uso futuro. Enfim, documentos acumulados por Épifânio Dória para comprovar, testemunhar e servir de base para trabalhos.

A aplicação de procedimentos arquivísticos a esse tipo de arquivo é possível e necessário na medida em que formam conjuntos orgânicos e autênticos, representantes das atividades que lhes deram origem (CAMARGO, 2009, p. 26-39).

Todo documento tem razão de ser e cumpriu com determinada função em algum momento da vida de um indivíduo ou entidade. No caso dos arquivos pessoais, são produtos de necessidades que pululam ao longo da vida de um indivíduo, ligados a atividades e funções sociais desempenhadas por ele.

Por assim dizer, os arquivos pessoais são representantes da vida de uma pessoa e devem receber um tratamento arquivístico efetivo, de forma a recuperar sua unicidade, organicidade e relação entre os documentos.

Segundo Heloísa Liberalli Bellotto (2008, p. VIII), é fundamental atentar para a "organicidade de seus conjuntos e de suas relações com o criador e com o contexto de produção". Assim sendo, temos de identificar o contexto em que os documentos foram criados e usados, buscando, dessa forma, o nexo entre o documento e a atividade e/ou o evento que the deu origem.

Trata-se de verificar a funcionalidade desses documentos e as marcas das funções neles incorporadas, em seu contexto de uso (CAMARGO \& COULART, 2007), isto é, verificar a função que o documento teve para a efetivação da atividade de determinado indivíduo. O documento, por assim dizer, não é uma construção, mas o resultado natural de todo o processo de que se originou e que foi ativado pelas necessidades do produțor.

Os documentos acumulados nos arquivos pessoais são documentos de arquivo $^{6}$, no sentido de que o contexto de produção de grande parte da documentação pode ser recuperado, sendo possível recriar as teias entre eles. Trata-se de tarefa laboriosa e complexa, pois os vínculos diretos com os processos e as

6 Segundo Lopez (2003), o documento de arquivo é constituído do suporte, da informação e do seu contexto de produção. 
funções responsáveis pela produção do documento devem ser identificados.

Os arquivos pessoais, da mesma forma que os arquivos administrativos, apresentam uma estrutura lógica da acumulação imediata, que dá margem a alguns tipos de documentos produzidos.

É imprescindível também que se busque a teia.de relações entreos documentos, ou seja, o vínculo existente entre eles. Dessa forma, podemos recuperar a conexão lógica e formal que liga um documento a outro por meio da necessidade.

O contexto de produção e acumulação está relacionado, portanto, às condiç̃êes de caráter intelectual, profissional, social, emocional, espiritual etc., já que os motivos que levam um indivíduo a produzir um documento estão atrelados às suas funções e atividades exercidas em sociedade $\mathrm{e}$, com isso, a eventos pontuais menos delineados ocorridos em sua vida. Assim, temos documentos materializados por conta dessas funções ocupadas e atividades realizadas.

De acordo com André Porto Ancona López (2003, p. 75):

[... mesmo os documentos que não se enquadram estritamente nas características típicas podem ser entendidos enquanto documentos de arquivo, desde que tenham sido produzidos no decorrer de alguma função inerente à vida do titular (instituição ou pessoa física) e tenham sido preservados como prova de tal atividade.

Experiências desenvolvidas por Ana Maria de Almeida Camargo; com os arquivos pessoais de Plínio Salgado e Adoniran Barbosa, somadas ao estudo de caso ora apresentado, apontam para o método funcional e o formato cronológico do instrumento de pesquisa (inventárió) como grande potencializador para a recuperação do contexto de produção dos documentos, do elo entre os documentos e, principalmente, para a recuperação da informação por intermédio da vasta possibilidade do uso de índices correlacionados aos verbetes, que são os eventos detectados na cronologia.

A tomar pela crescente onda de doações, por parte de familiareś, dos titulares de arquivos pessoais e do respectivo interesse de inúmeras entidades em receber esses conjuntos documentais, cremos que já é mais do que o momento de questionar os limites impostos a essa documentação quanto a sua natureza e validade no meio arquivístico.

Desse modo, para que a abordagem 
dada ao arquivo de Epifânio Dória fosse baseada na teoria arquivística, foi necessário percorrer o contexto funcional dos documentos e a compreensão de tal funcionalidade em sua dimensão temporal, assim como buscar o vínculo entre os documentos produzidos e acumulados a partir de um mesmo contexto de produção.

\section{Uma defesa sucinta de um método de trabalho com arquivos pessoais}

Fisicamente fragmentado em três instituições de documentação, não classificado, não organizado e não acondicionado de forma adequada, o legado documental de Epifânio Dória lança alguns desafios particulares. O fato de os arquivos pessoais não espelharem a totalidade de uma pessoa - da mesma forma que os

Ao analisarmos documento pordocumento, fizemos a ligação destes com a atividade mais imediata de sua produção. Os documentos apontaram, simultaneamente, para a atividade que os originou, ganhando sentido. a história da instituição - não impossibilita que esse conjunto documental seja encarado e receba tratamento arquivístico adequado. Apesar de estar fisicamente fragmentado, o legado documental inventariado não está intelectualmente desintegrado e comprometido. Ao entrar em contato com essa documentação, é possível perceber que ela não sofreu desvios nem perdas.

Assumimos que a natureza dispersa dos documentos não os exime do status de arquivo. Não é porque o arquivo de determinado indivíduo foi fragmentado após sua morte que a descrição não possa ser feita. Foi o que ocorreu com o arquivo de Epifânio Dória que, apesar da fragmentação, existe de forma íntegra e indivisível no inventário cronológico apresentado, levando-se em conta que este não sofreu perdas devido a intempéries, alienações ou desvios.

No caso da fragmentação de um arquivo, Ariane Ducrot (1998, ta fazer a classificação 
simultânea das partes, promovendo a unidade do fundo mediante inventário comum: localizá-los, identificá-los e reagrupá-los no papel, respeitando suas individualidades e ressaltando sua complementariedade. Ou seja, reconstituir o lugar original dos documentos no instrumento de pesquisa, sem intervir na ordem física da documentação e dos fundos.

Lembramos que a construção de um plano de classificação convencional é tarefa que antecede a elaboração de um inventário. No caso do arquivo Epifânio Dória, a documentação não estava classificada em nenhuma das instituições de custódia e não a classificamos antes da feitura do instrumento de pesquisa. Seguimos algo não usual no que diz respeito à recuperação da informação por intermédio dos instrumentos de pesquisa.

Ao analisarmos documento por documento, fizemos a ligação destes com a atividade mais imediata de sua produção. Os documentos apontaram, simultaneamente, para a atividade que os originou, ganhando sentido. Para tanto, foi imprescindível a criação de um banco de dados que, ao ser ali- mentado de forma padronizada, nos proporcionou uma eficaz recuperação de informações.

Outro ponto importante é o da organicidade. A documentação inventariada foi acumulada naturalmente pelo seu produtor e foi fruto das atividades e funções que exerceu em vida. Podemos afirmar, então, que possui como característica a organicidade dos documentos, ou seja, os documentos possuem vínculos que os ligam uns aos outros.

A busca dessa organicidade e desse elo documental não foi tarefa fácil, pois tratamos de um arquivo fisicamente fragmentado. No entanto, os procedimentos metodológicos utilizados no processo de análise e da inventariação da documentação facilitaram essa tarefa.

Ainda com relação à fragmentação do fundo, não tivemos como proposta reunir fisicamente essa documentação, até porque pertence juridicamente às instituições responsáveis por sua guarda. Reunimos intelectualmente a documentação do arquivo pessoal de Epifânio Dória em inventário único, 
endereçando devidamente esses documentos e fazendo a conexão entre eles, formando, com isso, agrupamentos documentais referentes a eventos e atividades da vida do seu titular.

A ausência de classificação e organização do arquivo pessoal por parte das instituições não comprometeu nosso trabalho, pois fizemos a classificação a partir do próprio inventário cronológico. Esse não comprometimento se deu, também, graças ao desenvolvimento de um banco de dados, no qual foram lançadas as informações extraídas dos documentos componentes do arquivo.

Essas informações foram filtradas e cruzadas, com auxílio de mecanismos oferecidos pelo programa utilizado (Excel e Access), possibilitando o encontro de eventos ocorridos e atividades desempenhadas pelo titular do arquivo, com os documentos produzidos e acumulados por ele, assim como a recuperação do elo entre essa documentação.

Os procedimentos adotados na elaboração do inventário diferiram-se dos usuais no que diz respeito ao tratamento dos arquivos pessoais. O mesmo ocorreu com relação à estrutura do inventário, que foi elaborada e formatada numa perspectiva linear. Criamos um inventário estruturado cronologicamente, em que eventos e atividades vivenciadas por um indiví- duo, durante sua vida, foram listados e vinculados aos documentos formadores do arquivo pessoal.

\section{Contextualização dos documentos e suas teias de relação}

A identificação do contexto de nascimento dos documentos, assim como do vínculo existente entre eles, é diretriz primordial no tratamento teórico-metodológico fornecido aos arquivos administrativos de instituições públicas e privadas e, também, aos arquivos pessoais.

Seguindo esse pressuposto teórico-metodológico, respeitamos os documentos do arquivo pessoal inventariado como um conjunto orgânico; cuja documentação se encontra ligada por um vínculo original; ou seja, os documentos foram contextualizados no seu meio genético de geração, atuação e acumulação.

Nos dizeres de Ana Maria de Almeida Camargo e Silvana Coulart (2007, p. 35-36) é preciso "admitir a necessidade de tratar o arquivo pessoal como conjunto indissociável, cujas parcelas só têm sentido se 
consideradas em suas mútuas articulações e quando se reconhecem seus nexos com as atividades e funções de que se originaram"

Levando-se em consideração que um indivíduo exerce determinadas funções e desenvolve inúmeras atividades durante sua existência, que somadas a essas funções e atividades desempenhadas decorrem vinculações e relações muitas vezes não delimitadas no tempo, e que esses eventos e acontecimentos são disparadores naturais da necessidade de produção de documentos, o método funcional permitiu identificar as atividades imediatas geradoras dos documentos (CAMARCO \& COULART, 2007).

A operação central da metodologia arquivística é a contextualização do documento, ou seja, a identificação do contexto em que o documento foi produzido. $\mathrm{O}$ arquivo de Epifânio Dória foi visto, portanto, como um conjunto inseparável, cujas partes tiveram sentido quando foram articuladas entre si e, também, com as atividades e funções que lhes deram origem. Buscamos, pois, os nexos internos e a teia de relações entre os documentos, mediante a caracterização de seu vínculo de origem.

Na óptica própria da arquivologia, procuramos a função de cada documento no contexto das atividades de Epifânio Dória.

A organização lógica do acervo, naárea de arquivo, é norteada pela funcionalidade, isto é, pela identificação do elo entre os documentos e as atividades que lhes deram origem. De modo a garantir que, individual ou coletivamente, os diferentes itens que o integram possam evocar ou representar, de modo inequívoco, as circunstâncias e o contexto que justificaram sua acumulação ou guarda (CAMARCO \& COULART, 2007).

Nesse processo, foram levadas em consideração as circunstâncias de produção e as relações intrínsecás que cada documento manteve com os demais itens que integram o arquivo?.

7 Foram apartados do conjunto e descritos em separado os documentos que não ofereceram datação, mas cujos contextos foram identificados ( 424 verbetes), bem como os documentos que apontavam para uma atividade não mensurável no tempo, como é o caso das relações de amizade e de companheirismo (398 verbetes). Já os documentos que não apresentaram datas e cujos contextos não puderam ser identificados de forma clara e segura (contexto: coleta de fontes e pesquisa), não foram inseridos no inventário, por os considerarmos desprovidos de valor documental e não agregadores de informações relevantes. 


\section{Cronologia de vida de Epifânio Dória}

Para auxiliar nossa caminhada na descrição e inventariação do legado documental acumulado por Epifânio Dória, ao longo dos seus 92 anos, foi de extrema importância a construção da cronologia de vida desse intelectual. Trata-se de uma tarefa imprescindível para o desenvolvimento do instrumento de pesquisa proposto.

É importante explicitar que essa cronologia de vida pode ser apreciada na própria estrutura do inventário cronológico do arquivo de Epifânio Dória.

Antes de iniciarmos a análise da documentação, recolhemos informações sobre a vida de Epifânio Dória a partir de diversas fontes, tais quais: textos produzidos e publicados pelo titular do arquivo; textos produzidos por outros a respeito de Dória; documentos administrativos das instituições com as quais esteve envolvido; documentos de arquivos pessoais de seus contemporâneos; matérias publicadas sobre ele em jornais do estado e documentação do seu próprio arquivo.
As fontes citadas acima atenderam determinados aspectos da vida de Epifânio Dória, mas não todos. Essa pe-, quena prévia da cronologia de vida do titular do arquivo foi importante para se ter uma noção inicial sobre suas atuações profissionais, funções desempenhadas, relações de amizade, vinculação institucional, dentre outras informações.

No entanto, esse pequeno apanhado de eventos não se comparou ao volume de verbetes gerados no decorrer da análise dos documentos do arquivo pessoal (4.346 verbetes). A partir dos 19.369 registros criados no nosso banco de dados, pudemos pontuar eventos de todas as espécies: nomeações e posses; cargos ocupados em instituições particulares; funções desempenhadas; cargos públicos ocupados; vinculações com dezenas de instituições, associações e sociedades; relações de amizade; aspectos mais íntimos de sua vida etc.

Na elaboração da cronologia de vida de Epifânio Dória, nos deparamos com a existência de eventos pontuais, muito bem reconhecidos, tais como jantares, casamentos, festas, homenagens, for- 
maturas etc. Encontramos diversas atividades de longa duração, que puderam ser mensuradas no tempo, a exemplo do desempenho de funções administrativas em equipes diretivas de diversas instituições culturais, educacionais e filantrópicas. E, por fim, atividades de longa duração, não mensuráveis no tempo, como o trabalho com a pesquisa científica, as relações de amizade, dentre outros.

A questão da disposição da linearidade do tempo no corpus do inventário cronológico é uma etapa importante no processo, sendo necessário remeter os documentos aos seus respectivos momentos temporais (leia-se, eventos e acontecimentos).

Após essa decisão, partimos para a criação de verbetes discursivos que representassem tais eventos. Cada verbete remete a atividades e/ou funções desempenhadas por Epifânio Dória e eventos dos quais participou ou, provavelmente, tenha participado.

Construídos a partir de informações colhidas, principalmente de seus documentos pessoais, tais verbetes são como dossiês aglutinadores que têm a tarefa de reunir, em tơrno de si, documentos produzidos, recebidos e acumulados a partir de distintos contextos e funções desempenhadas por Epifânio Dória ao longo de sua vida.

\section{Pensando o banco de dados}

A construção de um banco de dados, e seu preenchimento com informações extraídas de cada item documental do arquivo de Epifânio Dória, contribuiu para uma recuperação mais eficiente dessas informações no momento da elaboração do inventário cronológico do arquivo pessoal. Entretanto, vale ressaltar que o banco de dados por si só não resolve todos os problemas de uma pesquisa. É necessário cuidar de detalhes importantes, como a escolha dos campos, e as decisões referentes a determinadas regras e controle de vocabulário. Sem esses cuidados não poderíamos ter explorado o real potencial da ferramenta ora discutida.

Essa ferramenta foi desenvolvida no programa Excel, da Microsoft Office. Com a finalização da análise dos 35.193 documentos e a criação de 19.369 registros, fizemos a sua exportação para o pro- 
grama Access, . por questões de segurança, no momento da filtragem e/ou cruzamento de informações necessárias para a construção do inventário apresentado no estudo.

Com relação à definição dos campos formadores de tal ferramenta, tivemos a parcimônia de criar apenas os indispensáveis para a construção do inventário, evitando campos que trouxessem informações redundantes. Pensar o objetivo e a função que cada um desempenharia também foi primordial nesse momento, esclarecendo ainda o porquê da escolha de determinados termos em detrimentos de outros.

Como colocado por Johanna Smite Nair Kobashi, (2003) os campos são como pontos de acesso, que nos permitem chegar a documentos a partir de alguns aspectos preestabelecidos, nomeando critérios utilizados para agrupá-los.

\section{O inventário cronológico do} arquivo de Epifânio Dória e seus instrumentos auxiliares Como já enfatizado, o inventário é a no Quadro 7. própria cronologia de vida de Epifânio Dória. O instrumento equivale a uma classificação, na qual ocorre uma se-, quência de operações que, de acordo com as diferentes funções e atividades do produtor da documentação, tem como objetivo distribuir os documentos de um arquivo, fornecendo seus códigos de notação no acervo.

O inventário cronológico apresenta quatro informações básicas ao consulente: O ano referência dispõe, em ordem cronológica, os verbetes, que são numerados sequencialmente. 0 verbete informa sobre a atividade desempenhada ou o evento possivelmente vivenciado por Epifânio Dória, sendo que abaixo de cada um estão dispostos os documentos (espécies, tipos e formatos documentais, ou objetos) relacionados ao contexto de produção apresentado, seguidos do código de notação adotados por cada instituição. É importante ressaltar que a cada ano referência os verbetes ganham uma nova numeração e que o ano que não apresentou verbetes e documentos foi excluído do inventário, conforme possível verificar 
Quadro 1 - Exemplo geral do inventário cronológico - ano referência, dia-mês, verbete, documento e código de notação.

$1-1923$

2 - Permanece como diretor da Biblioteca Pública do Estado de Sergipe.

3- Carta de encaminhamento de livro: 1440.29.4986, 1440.29.4987, 1440.30.5170.

4 - Permanece como membro da Loja Maçônica do Cotinguiba, de Aracaju.

5 - Colabora com o periódico Sergipe Jornal.

6- Publica efeméride sobre o falecimento de Francisco José Martins, no Sergipe Jornal.

7- Crônica histórica: 1451.59.10042, 1453.66.11048.

8 - Publica efeméride sobre o falecimento de José Leandro Martins Soares, em coluna "Efemérides sergipanas", no Sergipe Jornal.

9- Carta de agradecimento: 1456.77 .12358$.

10 - É presenteado por Leocádio Correia, com o folheto "Pelo meu caminho".

11 - Folheto: 1517.27902

12 - (4 jan) Publica efeméride sobre o falecimento de Francisco de Paula Lindoso, no Sergipe Jornal.

13 - (21 jan) É eleito membro da Comissão de Redação dos Projetos da Hora Literária General Calazans, futura Academia Sergipana de Letras.

14 - Carta de convocação: A7.380.

15 - (27 jan) Ingressa como membro efetivo do Instituto Histórico e Geográfico de Sergipe.

16- Carta de aceitação: A7.381.

17-Diploma: A8.568.

18 - (31 jan) Soirée artística em festa do beletrismo, no Paco Municipal de Capela.

19-Prospecto: A16.1178[6].

$20-(\ldots)$

$21-1924$

22 - Permanece como diretor da Biblioteca Pública do Estado de Sergipe.

23 - Bilhete de encaminhamento de material: |481.179.19898.

24 - Carta de encaminhamento de questionário: 1481.179.19919.

25 - Carta de esclarecimento: 1481.179.19872:

$26-(\ldots)$

Fonte: Elaborado pela autora.

O dia/mês em que ocorreu o evento ou foi desempenhada a atividade, é disposto entre o número do verbete e a data. Alguns verbetes não possuem a informação dia/mês. Trata-se de uma atividade permánente e proativa desenvolvida por
Epifânio Dória, muitas vezes em concomitância com outras atividades semeIhantes, ou de um contexto que não teve dia/mês identificados.

Com relação aos verbetes que fornecem 
dia-mês, as informações encontram-se entre parênteses. Os verbetes que só apresentam a informação do mês estão dispostos antes dos que oferecem a data completa.

Os verbetes que apresentam evento ou atividade desempenhado(a) no decorrer de vários dias, a data apresenta o dia/início e o dia/fim, separados por traço.

Verbetes distintos ocorridos numa mesma data foram individualizados, evidentemente, por apresentarem diferentes documentos.

Com relação ao código de notação, os documentos do APES foram identificados com a letra (A) antes do código atribuído pela instituição; do IHCSE com um (I); e da BPED com a letra (B).

No final do inventário, criamos três grupos de documentação que não tiveram identificação de data e/ou de contexto de produção. Os documentos não datados, mas que tiveram seu contexto de produção identificado, geraram verbetes que foram listados no grupo denominado Sem data.

Documentos datados, mas com contexto de produção não mensurável no tempo, como o caso das relações de amizade e companheirismo, foram listados no grupo Correspondência passiva e ativa - rede de sociabilidade de Epifânio Dória. Nesse caso, listamos os nomes em ordem alfabética, iniciando pelo primeiro nome, pois em muitos casos só temos notícia de um único nome ou até mesmo apelido.

Os documentos que tiveram contextos de uso diversificado, como apontamentos e diversas espécies de documentos publicados em jornais, não tendo seu contexto de uso identificado, não foram listados no inventário, de acordo com explicação já dada anteriormente.

Comovisto, pormeio do inventário cronológico, agrupamos os devidos documentos pessoais de Epifânio Dória, explicitando suas relações com o mesmo evento ocorrido num determinado tempo e lugar. Para isso, uma minuciosa cronologia de vida do titular foi de fundamental importância, pois o grau de detalhamento está relácionado com a quantidade de eventos pontuados e catalizadores de documentos. Foi em torno do evento, observando o que ocorre em data e lugar determinados, que se realizou a operação classificatória básica, focalizando as circunstâncias mais próximas que justificaram o documento (CAMARCO \& COULART, 2007, p. 64). 
O índice geral, disponibilizado após o instrumento de pesquisa, remete o pesquisador ao inventário cronológico, apresentando o número de página em que nomes de pessoas, temas, instituições, lugares, obras e documentos constem representados - 0 mesmo ocorre para o índice de publicações de Epifânio Dória e outros autores. No inventário cronológico, o pesquisador tem acesso ao código de notação do documento de interesse. Com o códi-

\section{O índice geral,} disponibilizado após o instrumento de pesquisa, remete o pesquisador ao inventário cronológico, apresentando o número de página em que nomes de pessoas, temas, instituições, lugares, obras e documentos constem representados - 0 mesmo ocorre para o índice de publicações de Epifânio Dória e outros autores.

\section{go de notação em mão}

(espécie de endereço do documento no arquivo), o usuário pode solicitar o documento ao atendente da instituição (IHGSE, APES ou BPED).

Como já mencionado, um índice estratificado resolve algumas necessidades de pesquisadores que buscam certos aspectos da vida de um indivíduo. Complementar o trabalho com um índice multifacetado, que não abarque apenas nomes de pessoas, instituições e lugares que surgem ao longo do inventário cronológico, mas que englobe também, estratos significativos e diversificados da vida do titilar do arquivo é tarefa importante, a fim de atender aos mais minuciosos interesses do usuário do inventário apresentado.

É nesse momento que trabalhamos com a escala macro, priorizando sempre as ações do produtor do arquivo, ou seja, as funções e atividades desempenhadas em vida. É aqui que ocorre a classificação do arquivo pessoal. Classificaré trabalhar com uma sequência deoperações que,'levando em conta as distintas estruturas, funções e atividades da entidade ou indivíduo produtor, tem como objetivo distribuir os documentos de um arquivo. Essa tarefa torna-se mais rica e completa quando já temos concluído o inventário cronológico, uma vez que toda a documentação já foi trabalhada, possibilitando o enri- 
quecimento da pesquisa biográfica feita inicialmente.

Ao elaborarmos o quadro de classificação e assim criarmos a estruturação de um índice estratificado, devemos prezar pelas funções e atividades desempenhadas pelo titular do arquivo em questão. Criamos, então, categorias e subcategorias (quando necessárias). A ideia é justamente que tais categorias fiquem integradas, formando parte da estrutura de um todo (SANTOS, 2012, p. 60).

Optamos, como já colocado, por uma classificação baseada nas ações do produtor do arquivo, proporcionando uma classificação funcional. O objetivo é expor as funções e atividades desenvolvidas pelo titular do arquivo, deixando claro o elo entre os documentos (CONÇALVES, 1998, p. 12). Segundo Paulo Elian dos Santos (2012, p. 99), uma classificação que retrate as funções e atividades do indivíduo e que seja representativa destas, viabiliza a contextualização da produção documental.

Apresentamos abaixo, para fins didáticos, o índice estratificado transformado em tabela (Tabela 1). Observe que esta - apresenta, do lado esquerdo, as categorias (que são 12) e, do lado direito, suas respectivas subcategorias (quando existem) - vale lembrar que as categorias e subcategorias foram criadas com base nas funções e atividades desempenhadas por Epifânio Dória.

Tabela 1 - Índice estratificado para o Arquivo Epifânio Dória.

\begin{tabular}{|l|l|}
\hline CATECORIA & SUB-CATECORIA \\
\hline \multirow{4}{*}{ Vida familiar } & Educação e orientação dos filhos \\
\cline { 2 - 2 } & Celebrações \\
\cline { 2 - 2 } & Saúde \\
\cline { 2 - 2 } & Viagens \\
\hline Finanças & \\
\hline Vida social & Celebrações \\
\hline & Presentes recebidos \\
\hline \multirow{5}{*}{ Profissional } & Arquivo Público do Estado de Sergipe \\
\cline { 2 - 2 } & Biblioteca Pública do Estado de Sergipe \\
\cline { 2 - 2 } & Comércio \\
\cline { 2 - 2 } & Instituto Histórico e Ceográfico de Sergipe \\
\hline
\end{tabular}




\begin{tabular}{|c|c|}
\hline \multirow{7}{*}{ Profissional } & Juízo Municipal de Boquim \\
\hline & Montepio dos Funcionários Públicos do Estado de Sergipe \\
\hline & Mútua Construtora \\
\hline & Promotoria Pública da Comarca de Maruim \\
\hline & Seção Sergipe do Departamento de Imprensa e Propaganda (DIP) \\
\hline & Seção de Correspondência Regional do Estado de Sergipe \\
\hline & Secretaria Geral do Estado de Sergipe \\
\hline \multirow{33}{*}{ Vida Associativa } & Academia Alagoana de Letras \\
\hline & Academia Brasileira de Ciências Sociais e Políticas de São Paulo \\
\hline & Academia de Letras do Rio Grande do Sul \\
\hline & Academia Fluminense de Letras \\
\hline & Academia Paraibana de Letras \\
\hline & Academia Petropolitana de Letras do Rio de Janeiro \\
\hline & Academia Piauiense de Letras \\
\hline & Academia Polimática \\
\hline & Academia Sergipana de Letras \\
\hline & AccademiadiPaestum (Itália) \\
\hline & Associação Comercial de Sergipe \\
\hline & Associação de Intercâmbio Cultural \\
\hline & Associação Esperantista de Sergipe \\
\hline & Associação Internacional de Imprensa \\
\hline & Associação Marabaense de Letras \\
\hline & Associação Sergipana de Imprensa \\
\hline & Biblioteca América da Universidade de Santiago de Compostela \\
\hline & Caixa Beneficente de Maruim \\
\hline & Caixa Beneficente Manuel Cardoso \\
\hline & Centro Catarinense de Letras \\
\hline & Centro da Boa Imprensa \\
\hline & Centro de Ciências, Letras e Artes de Campinas \\
\hline & Centro de Cultura Intelectual de Campinas \\
\hline & Centro Operário de Sergipe \\
\hline & Centro Sergipano do Rio de Janeiro \\
\hline & Círculo Cultural do Instituto Maçônico de Cultura e Mérito \\
\hline & Círculo Universitário de Aracaju \\
\hline & Clube Carnavalesco Filhos da Arte \\
\hline & Clube Esperanto \\
\hline & Hora Literária de Santo Antônio \\
\hline & Hora Literária General Calazans \\
\hline & Instituto Arqueológico e Ceográfico Alagoano \\
\hline & Instituto de Cultura Americana \\
\hline
\end{tabular}




\begin{tabular}{|c|c|}
\hline & Instituto de Estudos Cenealógicos de São Paulo \\
\hline & Instituto do Ceará \\
\hline & Instituto Cenealógico Brasileiro \\
\hline & Instituto Cenealógico da Bahia \\
\hline & Instituto Geográfico e Histórico da Bahia \\
\hline & Instituto Histórico de Petrópolis \\
\hline & Instituto Histórico e Geográfico de Minas Cerais \\
\hline & Instituto Histórico e Ceográfico de São Paulo \\
\hline & Instituto Histórico e Geográfico de Sergipe \\
\hline & Instituto Histórico e Ceográfico do Acre \\
\hline & Instituto Histórico e Ceográfico do Espírito Santo \\
\hline & Instituto Histórico e Ceográfico do Rio de Janeiro \\
\hline & Instituto Histórico e Ceográfico do Rio Grande do Sul \\
\hline & Instituto Histórico e Ceográfico Paraibano \\
\hline \multirow[t]{15}{*}{ Vida Associativa } & Instituto Histórico e Ceográfico Paranaense \\
\hline & Instituto Histórico, Geográfico e Antropológico do Ceará \\
\hline & Liga de Defesa Nacional de Sergipe \\
\hline & Loja Maçônica Cotinguiba de Aracaju \\
\hline & Montepio Geral de Economia dos Servidores do Estado \\
\hline & OrdreBalzacien du Cheval Rouge \\
\hline & Recreio Clube \\
\hline & Rotary Club de Aracaju \\
\hline & Sociedade Beneficente dos Funcionários Públicos do Estado de Sergipe \\
\hline & Sociedade Bolivariana do Brasil \\
\hline & Sociedade de Numismática Brasileira \\
\hline & Sociedade Musical Santa Cecília \\
\hline & Sociedade Sergipana de Cultura Artística \\
\hline & Sociedade Sergipense União e Garantia \\
\hline & Universidade Ortológica \\
\hline \multicolumn{2}{|l|}{ Atuação política } \\
\hline \multicolumn{2}{|l|}{$\begin{array}{l}\text { Palestras, Discursos e } \\
\text { Conferências. }\end{array}$} \\
\hline \multicolumn{2}{|l|}{ Atividade discente } \\
\hline \multirow{2}{*}{$\begin{array}{l}\text { Representação em Co- } \\
\text { missões }\end{array}$} & Civis \\
\hline & Governamentais \\
\hline \multirow{2}{*}{ Vida acadêmica } & Pesquisas \\
\hline & Eventos \\
\hline \multirow{3}{*}{ Publicações } & 13 de Julho \\
\hline & Boletim da Associação Comercial de Sergipe \\
\hline & Boletim da Loja Maçônica Cotinguiba \\
\hline
\end{tabular}




\begin{tabular}{|c|c|}
\hline \multirow{29}{*}{ Publicações } & Cálamo (O) \\
\hline & Coleções, Dicionários e Tratados \\
\hline & Correio de Aracaju \\
\hline & Correio de Propriá \\
\hline & Correio de Sergipe \\
\hline & Cruzada (A) \\
\hline & Defesa (A) \\
\hline & Diário da Manhã \\
\hline & Diário da Tarde \\
\hline & Diário de Sergipe \\
\hline & Diário Oficial do Estado de Sergipe \\
\hline & Estado $(0)$ \\
\hline & Estado de Sergipe (O) \\
\hline & Estância (A) \\
\hline & Folha da Manhã \\
\hline & Cazeta de Sergipe \\
\hline & Gazeta do Povo \\
\hline & Gazeta Socialista \\
\hline & Jornal do Povo \\
\hline & Nordeste $(0)$ \\
\hline & Periódicos de outros Estados \\
\hline & Periódicos sem identificação \\
\hline & Pilheria (A) \\
\hline & Rádio (programas) \\
\hline & Razão (A) \\
\hline & Relatórios, opúsculos, discursos e cartas \\
\hline & Revista de Aracaju \\
\hline & Revista do Instituto Histórico e Ceográfico de Sergipe \\
\hline & Sergipe Jornal \\
\hline Homenagens recebidas & \\
\hline
\end{tabular}

Fonte: Elaborado pela autora.

Enfim, destacamos aqui a busca constante pelo contexto imediato de produção e acúmulo do documento, bem como a função que o documento analisado cumpriu quando foi produzido ou acumulado, dentro das atividades rotineiras do seu titular. Procuramos descobrir o que o documento manifestou no seu momento de produção e de uso, os envolvidos na sua produção, as práticas sociais e culturais da época em que foi produzido, ou seja, buscamos o sentido do documento. Portanto, durante a análise dos 
documentos buscamos entender as razões de sua produção e acumulação, sempre nos atentando para a possibilidade de diversos usos de um mesmo documento e circunstâncias de usos distintos.

Todo documento segue uma trajetória - nosso papel foi localizá-lo na linha cronológica do titular de determinado arquivo pessoal.

\section{Referências}

BELLOTTO, Heloísa Liberalli. Diplomática e tipologia documental em arquivos. 2. ed. Brasília: Briquet de Lemos Livros, 2008.

CAMARCO, A. M. de A.; COULART, S. Tempo e circunstância: a abordagem contextual dos arquivos pessoais: procedimentos metodológicos adotados na organização dos documentos de Fernando Henrique Cardoso. São Paulo: Instituto Fernando Henrique Cardoso (iFHC), 2007.

CAMARCO, Ana Maria de Almeida. Arquivos pessoais são arquivos. Revista do Arquivo Público Mineiro, Belo Horizonte, v. 45, n. 2, p. 26-39, jul./dez. 2009.

DUCROT, Ariane. Classificação dos arquivos pessoais e familiares. Estudos Históricos, Rio de Janeiro, v. 1, n. 21, p. 151-768, 1998.

FREITAS, Itamar. A escrita da História na "Casa de Sergipe": 1913-1999. São Cristóvão: Editora UFS; Aracaju: Fundaç̧ão Oviêdo Teixeira, 2002.

CONÇALVES, Janice. Como classificar e ordenar documentos de arquivo. São Paulo: Arquivo do Estado, 1998.37 p. (Projeto como fazer, 2).

LOPEZ, André Porto Ancona. Arquivos pessoais e as fronteiras da arquivologia. Gragoatá. Niterói, n. 154, p. 1-140, jul./dez.2003.

MEDINA, Ana Maria Fonseca (Org.). Efemérides Sergipanas. Aracaju: ]. Andrade, 2009. v. 1. Efemérides Sergipanas. Aracaju: ]. Andrade, 2009. v. 2. 
OLIVEIRA, Poliana Aragão Menezes. O que dizem as cartas? Formação e consolidação do IHCSEa partir de uma análise da correspondência de Epifânio Dória na década de 1930. 2004. 77 fls. Monografia (Licenciatura em História) - Universidade Federal de Sergipe, São Cristóvão. 2004.

SANTOS, Paulo Roberto Elian dos. Arquivos de Cientistas: gênese documental e procedimentos de organização. São Paulo: ARQSP, 2012.

SMIT, Johanna Wilhelmina; KOBASHI, Nair Yumiko. Como elaborar vocabulário controlado para aplicação em arquivos. São Paulo: Arquivo do Estado; Imprensa Oficial, 2003. 